\title{
O CRIVO DA CULTURA EM DIE AUSGESPERRTEN
}

\section{Dionei Mathias ${ }^{1}$}

Resumo: O romance Die Ausgesperrten ('Os excluídos'), publicado em 1980 pela autora austríaca Elfriede Jelinek, discute a questão do ódio em diferentes estratos sociais e as formas como essa emoção é articulada no contexto social. Assim, o ódio é representado nos primeiros círculos de socialização (na família e na escola), mais tarde surge também em esferas sociais mais complexas. Em todos esses espaços, os personagens se utilizam de discursos diversos para legitimá-lo, evidenciando a labilidade da cultura como barreira discursiva do princípio da violência. Apesar da maleabilidade da cultura no processo de configuração dessa emoção e sua livre exposição, os protagonistas acabam confrontados com um excesso emocional não compreendido, levando um à afasia e outro à destruição da família, com o objetivo de calar o indesejado.

Palavras-chave: Elfriede Jelinek; Die Ausgesperrten; cultura; ódio.

\begin{abstract}
The novel Die Ausgesperrten (Wonderful, Wonderful Times, 1990), published in 1980 by the Austrian writer Elfriede Jelinek, discusses the question of hate in different social strata and the ways this emotion is expressed in the social context. Thus hate is represented in the first circles of socialization (family and school), later it also appears in more complex social spheres. In all these spaces, the characters employ different discourses in order to legitimate it, showing the lability of culture as discursive barrier of the principle of violence. Despite the malleability of culture in the configuration process of this emotion and its open display, the protagonists end up confronted with an emotional excess which they do not comprehend, making one of them aphasic whereas the other murders his entire family, in order to silence the undesirable.
\end{abstract}

Keywords: Elfriede Jelinek; Die Ausgesperrten; Wonderful, Wonderful Times, culture; hate.

\footnotetext{
${ }^{1}$ Professor Doutor do Departamento de Letras Estrangeiras Modernas da Universidade Federal de Santa Maria. E-mail: dioneimathias@gmail.com
} 


\section{Introdução}

A vida em sociedade demanda do sujeito a repressão de seus impulsos egoístas. Sem isso, o princípio da violência reinaria, impossibilitando a vida pacífica. Violência, no seu sentido etimológico, remete à palavra "vis", ou força física, empregada no movimento de transgressão para o alcance do objeto cobiçado (MICHAUD, 2001, p. 10). Nisso, o ódio incita o ser a um comportamento agressivo, uma vez que em sua interpretação de realidade surge a sensação de injustiça. Essa leitura o move a empregar a força física para reaver aquilo que crê ser seu. O pacto da sociedade, contudo, prevê a renúncia da força para o bem comum. Para isso, faz-se necessário que uma rede de signos seja instaurada para assegurar uma determinada interpretação de mundo que coíba a expressão do ódio acompanhada pelo emprego da violência. Em Die Ausgesperrten ('Os excluídos', ainda sem tradução no Brasil), romance publicado em 1980 pela autora austríaca Elfriede Jelinek, muitas dessas interpretações perdem seu valor normativo e seu potencial coibente, de maneira que a animalidade se vê liberta, penetrando na vida social de uma forma cada vez mais desinibida.

Barreiras significativas que imperam de forma inconsciente sobre 0 indivíduo deixam de conter o princípio da violência, liberando um ímpeto agressivo de destruição. A modo de ilustração, o preceito judaico-cristão de honrar a pai e mãe não encerra somente uma função religiosa, mas abarca toda uma narração cultural que disciplina o sujeito a adotar um comportamento, cuja transgressão implicaria a impossibilidade da vida em sociedade. Para garantir a existência dessa primeira forma de sociedade, há todo um aparato de signos com a função de convencer o sujeito, já nos primórdios de sua socialização, da importância e, sobretudo, das vantagens - a vida eterna, mas também as regalias econômicas e psíquicas - de honrar e respeitar os pais. As relações entre pais e filhos raramente são livres de conflitos, sobretudo porque a distribuição de poder é desigual, num cenário, onde diversos sujeitos têm desejos prementes e, por vezes, difíceis de serem refreados. A família representa, portanto, o primeiro exercício de sociedade justamente por reunir 
diversos membros que têm de aprender a renunciar a seus ímpetos egoístas em nome da paz comum e, em especial, dos bens que estão em jogo. Esse exercício nada mais é que um reiterado ensaio de remodelar as emoções, sobretudo, daquelas cujo objetivo reside em destruir os obstáculos para 0 alcance do prazer. Em seu romance, Jelinek mostra como os crivos da cultura, cujo objetivo reside em inibir o surgimento da violência, perdem seu valor referencial. Assim a expressão do ódio na família e na escola (1), posteriormente também em círculos sociais mais complexos (2) se torna cada vez mais evidente, culminado num processo de legitimação do ódio (3).

\section{A expressão do ódio na família e na escola}

Os crivos da cultura começam a ruir, tão logo o sujeito se apercebe de que as vantagens talvez não sejam tantas ou insuficientemente interessantes para sua construção de identidade. Com a tomada de consciência dessa possível interpretação de mundo, os modelos culturais de comportamento incutidos por gerações a fio desvelam seu caráter artificial e acordado, e as redes de signos começam a perder seu valor social. Com isso, as barreiras impostas por convenções sociais para prevenir a expressão agressiva de emoções com ímpeto destrutivo também perdem seu valor referencial. Sem normas que o tolham, o comportamento agressivo surge inicialmente de maneira receosa, para logo em seguida afirmar-se com uma autoconfiança cada vez maior. A socialização desse dispêndio, comunicado em forma de agressões, inicia-se no seio da família. A palavra 'não' incute determinações indesejadas, inspirando o ódio daqueles que têm de submeter-se à vontade alheia. Com essa vontade alheia, impõem-se também as demarcações do poder:

Agressões na família demandam demarcações e podem levantar direta ou indiretamente a questão do poder, logo, mudar as estruturas familiares. Encargos conscientes ou inconscientes, delegações por várias gerações e tradições familiares também decidem em que medida a agressão define o estilo de comunicação familiar, se agressões podem ser permitidas e suportadas ou se um postulado por perfeita 
harmonia familiar transforma agressão em tabu (HÜLSHOFF, 2006, p. 165)

Esses diferentes estágios de comportamento e de expressão de ódio figuram na caracterização da grotesca família Witkowski: o pai, veterano de guerra e mutilado; a mãe, ex-professora, agora dona de casa e objeto das fantasias doentias de seu marido; e, por fim, os filhos Rainer e Anna, estudantes do ensino médio, todos eles com evidentes problemas sociais. Nesse universo deformado e tomado pelo incompreendido, Anna e Rainer apresentam uma sensação de ódio consciente pelos pais, mas ainda temem expressá-lo sem meandros:

Rainer odeia seus pais, mas também os teme. Eles o geraram e o mantêm agora, enquanto ele se entretém com a arte poética. O temor está atrelado ao ódio (Anna, que poderia obter um doutorado em questões de ódio), se não houvesse medo, seria possível economizar o ódio, e o que surge é uma indiferença sem graça. Então é melhor estar morto de uma vez (JELINEK, 2004, p. 12).

Mais que a geração, pesa o fato de que os pais sustentam os filhos, possibilitando a Rainer o estudo da literatura e a Anna o estudo da música. Com isso, há diversas vantagens de remodelar o ódio, de maneira a assegurar que certos confortos continuem proporcionando prazer. O medo surge do poder que os pais detêm de anular esse contrato e as respectivas fontes de prazer, obrigando os filhos a cuidar da própria vida. Para isso, no entanto, ambos ainda não apresentam maturidade anímica que lhes permita dar conta da complexidade que os circunda, embora não vejam a hora de livrar-se dos pais. Diante desse cenário de coação, precisam remodelar a expressão de seu ódio e encontrar um discurso que permita inserir essa incongruência em suas identidades. Essa tentativa de concatenação causal se dá com o argumento de sua superioridade em relação àqueles que não logram experimentar emoções intensas, preferindo vegetar no espaço insípido da indiferença. Os signos

"Aggressionen in der Familie fordern Grenzziehungen heraus und können direkt oder indirekt die Machtfrage stellen, also die Familienstrukturen verändern. Unbewusste und bewusste Aufträge, Delegationen über mehrere Generationen hinweg und Familientraditionen entscheiden ebenfalls darüber, ob und in welchem $\mathrm{Maß}$ Aggression den familiären Kommunikationsstil bestimmt, ob Aggressionen zugelassen und ausgehalten werden dürfen oder ein Postulat nach vollkommener familiärer Harmonie Aggression tabuisiert" (HÜLSHOFF, 2006, p. 165). 
culturais, portanto, voltam a ser manipulados para que condigam com as narrações de ódio intencionadas pelos protagonistas.

O crivo cultural cristão predominante também impede Hans, o representante da classe trabalhadora na constelação de personagens, de expressar abertamente seu ódio pela mãe. Ele lança às chamas uma pilha de cartas que a mãe havia preenchido com esforço para garantir o dinheiro que sustenta a família, e mais tarde cospe na sopa, simulando normalidade. Embora o ódio esteja latejando em suas entranhas e queira afastar-se da mãe, o interesse econômico e as redes culturais vigentes o impedem de dar rédeas soltas a suas emoções. O ódio impera, mas se articula sempre de maneira indireta, dentro dos parâmetros culturais válidos em seu espaço social.

Enquanto Hans não chega a refletir sobre seu relacionamento com a mãe nem procura expressar seu ódio abertamente, Anna e Rainer percorrem outro caminho, necessitando quase que obsessivamente a confrontação. Os parâmetros sociais e, com eles, os mecanismos de vigilância, controle e disciplina impostos pelas leis os forçam a conter e redirecionar sua emoção, recodificando e armazenando-a de outro modo. Dentro dos muros de casa, o crivo da cultura oficialmente continua imperando, mas, sem os mecanismos de controle existentes no espaço externo, surge um campo de ensaio para transgredir as barreiras culturalmente construídas. Isso obviamente produz o abandono da ética vigente e requer um saber até certo ponto consciente da feitura dessas regras. Diante da necessidade premente de concretizar sua agressividade, Anna e Rainer vão ao encontro desse conhecimento, para dar conta de suas turbulências físicas e anímicas. Dessa forma, o espaço familiar e a constelação de poder favorável lhes permitem ensaiar comportamentos libertos dos grilhões da cultura:

Anna e Rainer odeiam seus pais, porque a juventude frequentemente é precipitada e não se atém a compromissos. Eles muitas vezes cometem crimes malvados contra o pai odioso, imitando feito macacos e repletos de asco cada um de seus movimentos, arrancando-lhe as muletas, dando-lhe rasteiras (sabendo que ele só tem uma perna), cuspindo em sua comida e não the trazendo aquilo que pede (JELINEK, 2004, p. 35).

Como o pai já não possui a força física que lhe permitiria conter seus filhos e, sobretudo, porque ele se encontra numa situação em que depende da 
ajuda e boa-vontade alheia, os filhos podem desvencilhar-se dos preceitos éticos e encenar seu ódio de uma maneira completamente nova. Lorenz (2007, p. 56) interpreta esse comportamento como claro resquício, ou melhor, a repetição do passado nazista, indicando que a nova geração, no lugar de renovar, refaz o mesmo caminho. Sem passar pelo crivo da cultura ética, ambos revelam toda sua animalidade com uma liberdade que não teriam em outro contexto. O imperativo da compaixão pelo mais fraco e de respeito pelo progenitor perdem seu valor prescritivo, e o que prevalece é a expressão límpida do ódio, acompanhada por um comportamento cuja função reside em potencializar o deleite do momento. Esse deleite se revela no tom jocoso, aparentemente infantil e inocente das ações que dão matéria a suas emoções. A juventude, que ainda não tem muita experiência ética e cujo caráter ainda se encontra em fase de moldagem, assim indica o narrador, tem uma tendência maior a mostrar um comportamento sem as marcas da cultura.

O processo de transgressão sofre essa aceleração não somente pelo excesso de frustração e agressividade que borbulham no inconsciente dos jovens e turbam seu acesso à realidade. O exemplo paterno, cujas encenações sociais servem de modelo para os ensaios posteriores dos filhos, também contribui para que Anna e Rainer deem o primeiro passo em direção ao eticamente proibido. Esse modelo de comportamento ignora valores éticos e impõe desejos arbitrários com base na superioridade de poder:

Às vezes é um dia bem normal, e o pai escolhe arbitrariamente uma das crianças e bate nela aos gritos. Porque a criança não quer o que ele quer. Então a criança rema desamparadamente pelo ar, mas o conteúdo da criança se desprende do corpo e sobe um pouco mais, de onde tem uma visão melhor sobre o acontecimento horrendo (JELINEK, 2004, p. 34).

Com esse comportamento, o pai não revela somente que, para ele, os valores éticos são sistemas de signos arbitrários aos quais ele não tem de submeterse, ele indica também que, em sua visão, os próprios filhos não são seres com identidades próprias. O corpo do outro talvez represente a primeira barreira física e cultural que impede o ser possesso de ódio de materializar seus ímpetos agressivos. Nesse corpo, reside uma tradição cultural que prescreve comportamentos e limites. Essa parede cultural invisível praticamente não tem significado para o pai, que se utiliza dos filhos para satisfazer sua necessidade 
de extravasar a frustração que o acomete. Como objetos, ele pode usá-los para exteriorizar tudo que o incomoda, sem atentar aos signos culturalmente instituídos que preceituam a remodelação de emoções para assegurar a integridade do ser. Aqui o ódio está liberto da cultura e mostra sua face sem o menor intuito de dissimulação. Por outro lado, o pai se aproveita do papel social atribuído à figura paterna para legitimar sua arbitrariedade no tocante aos signos que circulam no seio familiar. Como pai ele tem o direito e o dever de educar seus filhos. Com esse escudo, culturalmente instituído, ele encontra um discurso de cujos signos se apropria para impor-lhe sua própria interpretação, cujo cerne está bem longe de uma preocupação altruísta.

Esse modelo de comportamento e ação social vivenciado no círculo da família acaba se transformando numa matriz geradora no inconsciente de Rainer e Anna. Assim, em sua próxima experiência de inserção social, que se dá na escola, esse comportamento volta a definir seu acesso à realidade, moldando, portanto, também as emoções que acompanham suas interações:

Que bagunça é essa, Witkowski um e dois, vocês poderiam, por favor, calar a boca ou querem que anote seus nomes no diário de classe? Não, a senhora não é pra anotar nada, somente seus fracassos particulares em seu caderno de anotações particular. Certamente, alguma coisa lhe malogra a cada semana. A senhora tem mau hálito, uma tez acinzentada desaprazível e grilhões muito grossos, senhora Professora (JELINEK, 2004, p. 52).

Sem o crivo da cultura, que prescreve respeito ao ser humano, os irmãos Witkowski reagem com uma expressão de ódio sem grandes rodeios. As agressões verbais em forma de ofensas têm o intuito de acometer a identidade e dignidade da professora, indicando sua inferioridade física e sua incapacidade de encenar uma narração pessoal que condiga com o modelo de êxito, existente em sociedades meritocráticas. Os irmãos ignoram duas redes de signos que servem de barreira para a contenção de emoções agressivas. Por um lado, ignoram o papel social da professora, que detém um poder institucionalizado dentro do microcosmo social da sala de aula. Ao ofendê-la abertamente diante da classe, eles quebram o contrato social para satisfazer sua necessidade de expor todo seu ódio. Por outro lado, assaltam sua integridade pessoal, protegida, no mais das vezes, pelos princípios éticos de respeito ao próximo, minorando sua identidade e sua legitimidade como ser 
humano pertencente àquele espaço social. Com isso, transgridem, ou melhor, desconsideram os limites construídos por meio de signos da narração pessoal.

A professora, no entanto, também transgride barreiras culturais para expressar seu desgosto de forma mais direta. A utilização do vocativo numerado revela sua intenção de mostrar seu desprezo por eles, transformando suas identidades em produtos intercambiáveis, diferenciados somente por algarismos. Ademais, faz uso de seu poder como instrumento de ameaça, crente de que com isso a materialização de suas emoções tem prioridade absoluta. O comportamento tanto da professora como dos irmãos mostra a labilidade da cultura no que concerne à modelação de emoções. $O$ clima da classe indica uma animosidade que há muito abandonou o estágio de latência para aflorar sem receios ou empecilhos culturais nas interações cotidianas.

\section{O ódio em esferas sociais mais complexas}

Com experiências de transgressão nesses dois espaços sociais elementares, o passo para sua aplicação num campo mais complexo e com maiores riscos se transforma em algo necessário para a coesão da própria construção identitária. A primeira cena do livro resulta, portanto, de uma série de ensaios anteriores que proporcionaram aos irmãos o conhecimento psíquico para desbravar e ir além dos limites do proibido. Rainer e Anna abandonam os espaços sociais restritos, com pessoas conhecidas e reações previsíveis, para adentrar um meio cujo controle Ihes escapa. Para isso, atacam na escuridão e em grupo, testando assim novas esferas de expressão do ódio.

Rainer e Anna desconstroem diversos estratos culturais de maneira a poderem materializar sua emoção sem inibições. Primeiramente envolvem duas outras pessoas, Hans Sepp, o trabalhador, e Sophie Pachhofen, representante da classe alta. Ao compartilharem suas intenções a terceiros e inseri-los em suas maquinações, o ódio toma outra dimensão. Eles quebram o contrato social da inexistência e inadmissibilidade do ódio, articulando abertamente a necessidade de converter suas emoções em agressão física. Para terem êxito, precisam combater a educação ética de Hans e Sophie, quebrando uma série de tabus. Ou seja, o limite da narração ética alheia é |24| Revista Eletrônica Literatura e Autoritarismo, № 25 - janeiro a junho de 2015 - ISSN 1679-849X http://cascavel.ufsm.br/revistas/ojs-2.2.2/index.php/LA/index 
desconstruída, potencializando assim as possibilidades de expressão do ódio.

O segundo aspecto é a visão da vítima, ou seja, o encontro do olhar da pessoa que, contorcida pela dor, pede piedade e o olhar do agressor que, a despeito de vulnerabilidade do ser, não hesita em destruir o corpo alheio. $O$ olhar da vítima - do ser etimologicamente sacrificado aos Deuses - instaura a consciência do sacrifício sob as perspectivas de ambos os lados. Desviar, portanto, o encontro das consciências ameniza a violência, construindo uma narração da realidade passível de ser suportada. Com o olhar, dois corpos se encontram e se impõem como limites justamente pela possibilidade de produção de realidades indesejadas. O grupo não hesita em atacar com uma intensidade ainda maior, desconstruindo a parede da inconsciência. Anna até mesmo procura o contato visual, tamanho é seu ódio e sua necessidade de transformá-lo em matéria que adentre a consciência dela e a da vítima.

Por fim a escolha da vítima representa uma transgressão. Trata-se de uma pessoa aparentemente boa, na verdade, de um membro da sociedade que cumpre com todas suas obrigações, leva uma vida regrada e é uma pessoa de família. Ou seja, esse homem, receptor do ódio, representa alguém que internalizou todos os mandamentos do contrato social. Ao contrário do pai e da professora que se utilizam de seu poder para impor suas vontades aos outros, provocando, portanto, um desgosto natural no embate de desejos, a legitimação do ódio e da agressão para com a vítima escolhida ao acaso se torna problemática, pois além de desprezar as redes culturais que reprimem esse comportamento, a narração do ódio requer uma construção especial cujos signos já não podem ser derivados de conceitos de justiça. Isso significa que os protagonistas ignoram a necessidade de construir redes causais legitimáveis em sociedade, desconstruindo assim uma prática essencial para a interação social.

\section{A legitimação do ódio}

Apesar de sua necessidade obsessiva de transpor todas as convenções a fim de granjear uma liberdade mais ampla para articular seu ódio, o grupo liderado pelos irmãos também experimenta a urgência de elaborar uma narração que revele sua orientação teleológica e, com ela, a causalidade de 
seus atos. De acordo com essa encenação, a violência não representa senão um ato de gratuidade, desprovido de qualquer interesse para além da agressão em si:

Violência acompanhará nosso crime, Anni, você também não é dessa opinião? Mas não se pode cometê-lo num estado de agitação, não pensado como forma de ab-reação, mas é preciso se dedicar a ele com sangue-frio, o estado de agitação tem de ser evitado. Você tem toda razão (Anna), pois assim o crime se tornaria em algo secundário, quando deve ser 0 aspecto principal (JELINEK, 2004, p. 184).

Por mais que os irmãos queiram se libertar das imposições culturais, eles também precisam reconstruir seus atos, de modo a integrá-los em suas identidades. Essa integração de seus atos não funcionaria, se não tivessem todo um aparato que concatenasse ação, interação, atos e autorrepresentação. No entanto, sua narração está baseada em valores inenarráveis na sociedade, sobretudo porque aparentemente o objetivo central da violência não é transformar-se em instrumento para alcançar uma determinada interpretação de justiça, mas ser exercida como ato em si. Para materializar seu ódio e narrar sua interpretação do mundo, Rainer diversas vezes recorre ao existencialismo, um discurso intelectual, representável em todos os espaços. Com essa rede discursiva, ele divisa uma orientação teleológica com a qual crê poder justificar e encenar a violência em seus diferentes aspectos. "É preciso dar pancadas nas pessoas não por ódio, mas sem motivo nenhum, como finalidade em si, adverte o irmão Rainer" (JELINEK, 2004, p. 11). Sua argumentação revela a necessidade de uma máscara cultural que lhe permita exteriorizar as emoções que o acometem, mas que são inadmissíveis se expostas patentemente. $O$ discurso filosófico, portanto, serve de instrumento, proporcionando signos, por meio de interpretações deturpadas, que permitem a existência do ódio na realidade cultural. Jelinek reiteradamente introduz esses resquícios da tradição intelectual, para mostrar, entre outras coisas, que servem de instrumentos para justificar estados emotivos, comportamentos, ações. No mais das vezes, as personagens não chegam a dialogar com a herança cultural, eles simplesmente a utilizam para seus fins.

Nesse caso o ódio passa pelo crivo de um discurso específico, de modo a melhor adequá-lo aos moldes de construção e narração de identidade. Sua artificialidade, no entanto, se patenteia tão logo Rainer e Anna começam a |26| Revista Eletrônica Literatura e Autoritarismo, oㅡ 25 - janeiro a junho de 2015 - ISSN 1679-849X http://cascavel.ufsm.br/revistas/ojs-2.2.2/index.php/LA/index 
interagir e desenvolver suas ideias. Rainer usa o existencialismo como meio para impressionar intelectualmente a todos que o circundam, para de tal forma estabelecer sua superioridade no grupo em que circula. Partindo dessa encenação, poderia assumir-se que o ódio de Rainer provém de uma posição intelectual que vangloria qualquer ato gratuito, implicando a conformidade de seu comportamento com um discurso elitista e, sobretudo, justificando sua expressão desmesurada. Suas argumentações truncadas, no entanto, e a constante justaposição de contextos díspares revelam que suas motivações se originam antes na necessidade de granjear o interesse alheio. Numa mesma linha de pensamento, a personagem Rainer explana a beleza da violência, especialmente no que concerne à dinâmica do corpo ao desfazer-se diante do impacto da força alheia, e menciona o projeto - somente imaginado, já que seus pais não possuem os recursos necessários - de comprar móveis franceses. O tertium comparationis está na beleza das superfícies: por um lado, os músculos que impõem sua presença e cedem à força, por outro, as superfícies dos móveis de design francês que se assemelham em suas formas a corpos elásticos.

O ódio, nessa argumentação, potencializa a percepção da beleza, embora seu objetivo resida na destruição. Por trás dessa construção causal atraente, esconde-se a necessidade de Rainer de conquistar a admiração do grupo e, em especial, a de Sophie, cuja beleza física, independência financeira e superioridade anímica o impressionam de tal forma, que gostaria incorporá-la ou, isso não sendo possível, ao menos aproximar-se de sua aura. O crivo da cultura se materializa na necessidade de comprovar mediante signos visíveis a hierarquia social e de imprimir às ações o selo inconfundível de originalidade. Como Janz (1999, p. 73) indica, "em Die Ausgesperrten, os jovens não estão interessados em educação (Bildung), mas sim em poder e ascensão social a qualquer preço". Aparentemente, apenas a unicidade pode salvar o indivíduo da homogeneidade social. Para isso, é necessário desenvolver um arsenal criativo a fim de representar a identidade de tal forma que sua imagem permaneça indelevelmente impressa na memória das pessoas de referência. $O$ ódio passa por esse crivo e se adapta à lógica de representação:

Só o grande o número de leis é que causa o crime (Rainer). Essas leis e outras semelhantes não valem para mim, mas 
somente para aqueles que necessitam de direção. Eu sou mais um líder e no futuro quero, por exemplo, liderar também você, meu amor. Eu tenho um tal ódio em mim que dá pra dois. Quem é esse segundo cara por quem você tem ódio? Eu, por exemplo, não preciso de ódio, eu posso fazê-lo sem a menor finalidade. Eu quero saber do que eu deveria ter algum ódio (JELINEK, 2004, p. 129).

Embora Rainer tente envolver seus argumentos num discurso de superioridade e legitimar seu ódio com elementos de originalidade, Sophie imediatamente reconhece suas estratégias, indicando a impropriedade da lógica que Rainer tenta imprimir em sua encenação. Se a gratuidade está no centro de suas ações, como ele enfatiza reiteradamente, o ódio não faz sentido. Enquanto a gratuidade não encerra finalidade, o ódio sempre contém um momento de orientação teleológica. Ou seja, ela entrevê em suas incitações o desejo premente de aproximar-se dela e tornar-se de fato um líder, o que ele definitivamente não logra ser.

Nessa discrepância entre ser e parecer, encontra-se a fonte de seu ódio. Rainer não suporta a dor que se impõe ao vislumbrar uma imagem de si que não consegue admitir. A consciência de sua verdadeira posição no espaço social lhe é tão dolorosa, que necessita encenar ininterruptamente a identidade que de fato desejara ter. Esse embate, não obstante, entre identidade desejada e identidade socialmente legitimada - entre desejo e realidade - causa uma frustração inconsciente que precisa de alguma forma ser canalizada. O uso de discursos intelectuais o ajuda a inserir em sua consciência pessoal e em sua narração social a presença do ódio, sem, no entanto, reconhecer suas verdadeiras causas.

O ódio surge a partir da frustração no processo de encenação social e no conflito com a alteridade pessoal reprimida. A dor se materializa perante a identidade não reconhecida e, sobretudo, diante do outro eu inadmissível que habita seu inconsciente e, por vezes, adentra de forma mutilada sua reflexão, ultrapassando sua capacidade de ordenar o real que o envolve. A única forma de comunicar o desconforto que o acomete, questionando sua legitimidade existencial, é o ódio: ódio pela sociedade que não aceita sua encenação de identidade, ódio pelo outro eu que se obstina em querer questionar a imagem estabelecida.

Anna segue uma lógica semelhante. Com suas demonstrações de 
violência, também ela quer, em primeiro lugar, chamar a atenção do mundo sobre si, já que o roubo de bolsas lhe parece infantil e insuficientemente eficaz para granjear olhares sobre sua existência. Como Rainer, ela experimenta a necessidade de diferenciar-se da massa, para desse modo materializar sua superioridade. Para isso, ela despreza valores burgueses como a limpeza e a harmonia caseira de famílias pacíficas. Em analogia ao comportamento de seu irmão, ela reformula seu ódio com outros signos, inserindo redes discursivas passíveis de serem integradas em sua identidade. Ao atrelar seu ódio ao desprezo que sente por valores vigentes no espaço que habita, ela narra sua identidade a partir de uma posição hierarquicamente superior. Representado dessa forma, o ódio se transforma num instrumento de encenação que lhe permite autodefinir-se aparentemente sem influências externas. A labilidade dessa narração, contudo, se revela, tão logo alguém se atreve a questioná-la:

Anna sente um frio enorme, porque ela descobriu que talvez ainda não esteja completamente pronta e ainda precise continuar com sua evolução, o que ela rechaça. Ela já atingiu um estágio máximo e não tem mais nada a perder. Que algo ainda deva aparecer pela sua frente a enlouquece, pois para ela todas as chances já se foram, e uma vontade de matar lhe sobe das entranhas. Nada mais pode acontecer, somente 0 nada absoluto, no qual não há parâmetros morais, que esse estudante certamente ainda tem, mesmo falando de um modo rude com sua mulher (JELINEK, 2004, p. 112).

Essa passagem se encontra num contexto em que Anna acaba de tentar impressionar as pessoas que a circundam com seus dotes musicais, isto é, seu maior orgulho pessoal. Um estudante se aproxima e lhe indica, sem meandros, que sua competência musical não é suficiente para tocar naquele local. Todas as certezas que alimentava até aquele momento se transformam em ruínas em decorrência de algumas poucas palavras oriundas de um desconhecido, o que desperta seu ódio brevemente adormecido perante a chance de encarnar uma identidade centrada na música. Desfeita a narração antes desejada, ela volta então a modelar seu ódio com discursos extremistas, rejeitando normas morais e enfatizando sua superioridade por meio da diferença absoluta.

O ódio mediado pelo desprezo e pela negação de normas remonta a sua dignidade ferida. Por mais que seu ímpeto de chamar a atenção também esteja matizado por vaidades infantis, ela atribui uma importância muito grande a suas habilidades musicais. Nessa representação, encontra-se uma possibilidade de 
integração social, baseada numa narração de identidade que lhe permitiria existir com todas suas imperfeições e inadequações sociais. Com essa chance novamente destruída, não lhe resta outra coisa, senão resistir com agressões. Essa resistência se manifesta em forma de ódio, um ódio transvestido de desprezo e negação, para encobrir as verdadeiras motivações que a impelem, em especial sua fraqueza e sua necessidade de reconhecimento.

\section{Considerações finais}

Em Anna, o ferimento ininterrupto de dignidade, o aniquilamento da identidade e a falta completa de perspectivas no tocante a modelações pessoais no espaço social provocam uma afasia em cujo núcleo reside o ódio pelo mundo. Esse ódio já não é mais traduzido por signos de discursos alternativos enfatizando sua superioridade, mas se transforma em algo estático impassível de ser remodelado, senão pelo silêncio completo. A representação no ódio se restringe à tradução dada pelo corpo, pois os signos da cultura não abarcam a intensidade da ruína.

Rainer, por outro lado, pelos mesmos motivos, segue um caminho diverso. Embora não suporte a realidade que a sociedade lhe impõe, também ele precisa exteriorizar seu ódio de alguma forma perante a falta completa de reconhecimento. Se no primeiro momento ele ainda afirma cheio de vaidades que seria capaz de cometer atrocidades, encontrando nessa autoencenação uma forma de captar a atenção alheia, ele se depara num determinado ponto de sua construção identitária com um estágio no qual já não logra mais manipular signos culturais de forma que estes lhe permitam representar algo que ele não é e que a sociedade não legitima. Perante o fracasso dos signos e diante dessa realidade que lhe foge do controle, impondo-se de uma maneira insuportável, não lhe resta outra coisa senão destruir a fonte primária geratriz de signos, que é o corpo. A destruição total da carne permite a transfiguração e evasão do ódio. Sem signos que pudessem figurar ou traduzir a intensidade dessa emoção, somente o corpo, com o grito da dor, poderia materializar todas as dimensões do ódio. 


\section{REFERÊNCIAS}

HÜLSHOFF, Thomas. Emotionen. Terceira edição, München/Basel: Ernst Reinhardt Verlag, 2006.

JANZ, Marlies. Mythendestruktion und 'Wissen'. Aspekte der Intertextualität in Elfriede Jelineks Roman 'Die Ausgesperrten'. In: Text + Kritik: Zeitschrift für Literatur, No 117, 1999, p. 39-50.

JELINEK, Elfriede. Die Ausgesperrten. Hamburg bei Reinbek: Rowohlt, 2004.

LORENZ, Dagmar C. G. Ideology and Criticism in the Novel and the Film Die Ausgesperrten [Wonderful, Wonderful Times]. In: KONZETT, Matthias Piccolruaz; LAMB-FABBELBERGER, Margarete (Orgs.). Elfriede Jelinek: Writing Woman, Nation and Identity. Madison, NJ: Fairleigh Dickinson, 2007, p. $55-75$.

MICHAUD, Yves. A violência. Tradução de L. Garcia. São Paulo: Ática, 2001. 